\title{
CHARACTERISATION AND MONITORING OF TI6AL4V (ELI) POWDER USED IN DIFFERENT SELECTIVE LASER MELTING SYSTEMS
}

\author{
K. Thejane ${ }^{1 *}$, S. Chikosha² \& W.B. du Preez ${ }^{1}$
}

\section{ARTICLE INFO}

\section{Article details}

Presented at the $18^{\text {th }}$ Annua International RAPDASA conference held from 8-10 November 2017 in Durban, South Africa

Available online $\quad 22$ Nov 2017

Contact details

kthejane@cut.ac.za

\section{Author affiliations}

1 Department of Mechanical Engineering Central University of Technology, Free State, South Africa

2 Material Science and Manufacturing CSIR, Pretoria, South Africa

DOI

http://dx.doi.org/10.7166/28-3-1853

\section{ABSTRACT}

The characterisation and monitoring of Ti6Al4V (ELI) feedstock powder is an essential requirement for the full qualification of medical implants and aerospace components produced in selective laser melting systems. Virgin and reused samples of this powder were characterised by determining their physical and chemical properties through techniques complying with international standards. This paper presents the results obtained for Ti6Al4V (ELI) powder of two different particle size distributions received from the same supplier. The characteristics of these powders after several reuse cycles in two different selective laser melting systems are also presented and discussed.

\section{OPSOMMING}

Die karakterisering en kontrolering van Ti6Al4V voermateriaalpoeier is ' $n$ kernvereiste vir die kwalifisering van mediese implantate en ruimtevaartkomponente wat deur middel van selektiewe laser smelt stelsels produseer word. Nuwe en herbruikte monsters van hierdie poeier is gekarakteriseer deur hul fisiese en chemiese eienskappe te bepaal deur tegnieke wat aan internasionale standaarde voldoen. Die resultate vir Ti6Al4V poeiers met verskillende partikelgrootteverdelings van dieselfde verskaffer word hier voorgehou. Die karakteristieke van hierdie poeiers na etlike hergebruik siklusse in twee verskillende selektiewe laser smelt stelsels word ook voorgehou en bespreek.

In recent years, selective laser melting (SLM) has gained broad acceptance as a manufacturing technology for the production of high-value parts, such as medical implants and aerospace components. The most prominent alloy used to produce these parts is Ti6Al4V, with the extra low interstitial grade Ti6Al4V (ELI) being the preferred alloy for medical implants. The advantages of the reduced levels of oxygen and nitrogen in this alloy are improved ductility and better fracture toughness, which are essential for a good fatigue life [1]. However, for full acceptance of this manufacturing technology in demanding industries such as these, the qualification of the SLM process chain in compliance with international standards is imperative.

Various teams are working around the globe towards the qualification and certification of SLMproduced parts. An example is the South African national programme, Qualification of Additive Manufacturing of Ti6Al4V for Medical Implants and Aerospace Parts. This programme entails comprehensive and systematic research aimed at establishing a database of material and process data needed for qualification of the SLM powders, SLM processes, and post-process treatments used by the collaborators for medical and aerospace applications [2,3]. As the main input to the SLM process, the programme requires the characterisation of the feedstock powder used in the different SLM systems to ensure that its properties comply with the standard specification [2]. Due to the high cost of the Ti6Al4V powder, reuse of the powder not consumed during the SLM building process, for as long as possible, is an important driver. Therefore the properties of the powder remaining in the SLM system have to be monitored after successive build cycles. 
Studies of the reuse of Ti6Al4V powder in both selective laser melting (SLM) and selective electron beam melting (SEBM) systems have been published [4,5]. Each of these studies reports the observed changes in the chemical and physical properties of recycled Ti6Al4V powder, and suggests modifications to the manufacturing process to preserve the powder.

Tang et al. [5] examined the reuse of a batch of Ti6Al4V (ELI) powder in an ARCAM selective electron beam melting (SEBM) machine, without topping up the powder in the dispenser of the machine with virgin powder, for 21 build cycles. In this process a temperature of $550^{\circ} \mathrm{C}$ was maintained in the build chamber. After four cycles, significant changes in the chemical properties were observed. Apart from this, the particles were no longer spherical, and satellites were attached to larger particles after 21 cycles. They concluded that the Ti6Al4V (ELI) powder could not be reused for more than four times unless the reused powder was mixed with virgin powder.

Seyda et al. [4] investigated the recycling process of Ti6Al4V powder (size range $20 \mu \mathrm{m}-50 \mu \mathrm{m}$ ) over several months, using a laser melting process. The powder was reused for 12 cycles without introducing virgin powder into the machine. This process was carried out at room temperature, and after each build the collected powder was sieved and reintroduced into the subsequent build cycles. They found that the powder size distribution (PSD), density, and flowability were affected by the reuse of powder from the same batch. An increase of the size range towards coarser particles $(51.18$ $\mu \mathrm{m}-100 \mu \mathrm{m})$ was observed. The density increased and the flowability improved. Seyda et al. [4] concluded that reuse of the powder was affected by laser heat during the SLM process and by the particles that came off the finished part after every build.

In the current study, a Ti6Al4V (ELI) primary powder batch, divided into two secondary batches of different particle size distributions, was obtained from TLS Technik GmbH. These two powder batches were used in the direct metal laser sintering (DMLS) system at the Central University of Technology, Free State (CUT) (size range: $<40 \mu \mathrm{m}$ ) and the Concept Laser system of Stellenbosch University (SU) (size range: 25-55 $\mu \mathrm{m}$ ). The as-received powder was characterised for each of these batches. Subsequently, the powder properties were monitored after increasing numbers of reuse cycles in these two SLM systems. In the DMLS system the powder was recycled up to 25 times, while in the Concept Laser system it was recycled for 10 cycles.

\section{SAMPLING OF POWDER FROM THE TWO SLM MACHINES}

Ti6Al4V (ELI) powder was used to fabricate a variety of parts in both the DMLS and the Concept Laser systems. During this study the system parameters were kept constant, and any contamination of the powder or handling procedures that could affect powder properties were avoided.

The as-received powder for use in the DMLS system showed poor flowability; so it was dried at $80^{\circ} \mathrm{C}$ for five hours and sieved before use. The powder was reused in up to 10 cycles without the addition of virgin powder; only then did the remaining volume of powder in the dispensing container become insufficient for the next build. Consequently, virgin powder was added and mixed with the used powder remaining in the machine for the $11^{\text {th }}$ build and beyond. Samples were taken after each build using a keystone sampler device that was dipped into the powder to extract representative powder samples from locations at the top, middle, and bottom of the powder container [2]. Powder samples for characterisation were taken of the as-received virgin powder, as well as after cycles 3, 10, 11, 20 , and 25.

In the Concept Laser system, the as-received powder had acceptable flowability, and was directly used for the first build. At the end of each production cycle the unused powder was collected and returned to the dispensing container. The system provides an efficient recycling process, ensuring that the operator has no contact with the powder and that the powder has no exposure to air during this process. The virgin powder samples were scooped [6] from the machine before the first build, and unused powder samples were collected after each build during the mechanical sieving process. Powder samples were collected from below the vibrating sieve after every cycle. Eventually, 10 builds were performed without topping up with virgin powder. Powder samples for analysis of their physical and chemical properties were taken from the virgin powder, as well as after cycles 2,3 , and 10.

Figure 1 gives an overview of the powder characterisation performed on the Ti6Al4V (ELI) powder used in the DMLS and Concept Laser systems. 


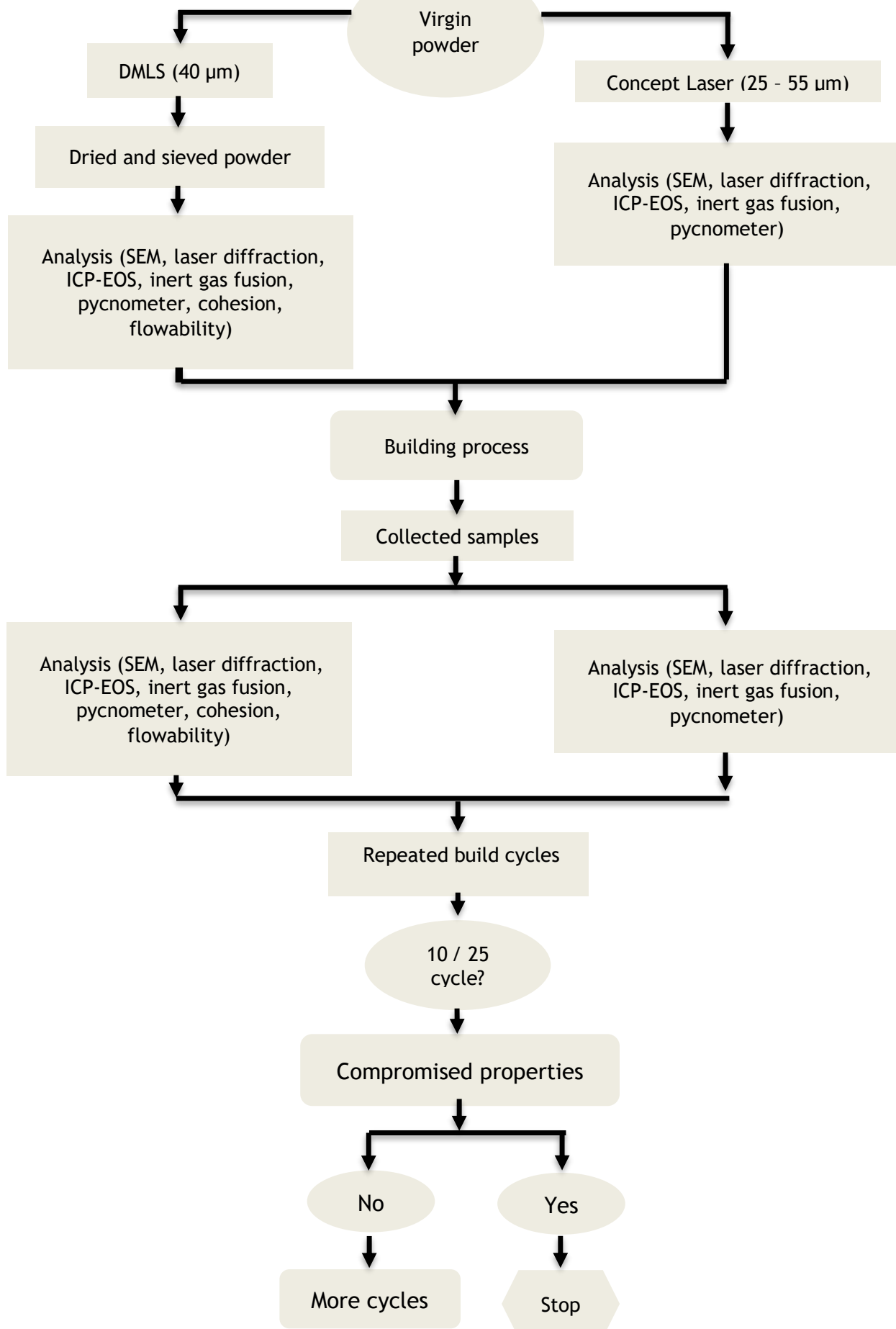

Figure 1: The powder characterisation procedure applicable for both DMLS and Concept Laser systems

\section{CHARACTERISATION TECHNIQUES}

Table 1 summarises the powder characterisation methods used in this study. The analysis methods used for the characterisation of the powder samples complied with the international standards specified in the ASTM F3049-14 standard guide [7]. 
Table 1: Techniques / methods used for powder characterisation

\begin{tabular}{|l|l|l|}
\hline Characteristic & Method/Technique & Instrument \\
\hline $\begin{array}{l}\text { Elemental } \\
\text { composition }\end{array}$ & $\begin{array}{l}\text { Inductively coupled plasma-optical emission spectroscopy } \\
\text { (ICP-OES) }\end{array}$ & SPECTRO ARCOS \\
\hline Gas content & $\begin{array}{l}\text { Inert gas fusion } \\
\text { LECO combustion }\end{array}$ & $\begin{array}{l}\text { ELTRA OHN 2000 } \\
\text { LECO OHN 836 }\end{array}$ \\
\hline Morphology & Scanning electron microscopy (SEM) & JEOL JSM-6510 \\
\hline Size distribution & Laser scattering & MICROTRAC SI/S3500 \\
\hline Density & Pycnometer & AccuPyc II 1340 \\
\hline $\begin{array}{l}\text { Cohesion } \\
\text { Flowability }\end{array}$ & Rheology & $\begin{array}{l}\text { FT4 powder } \\
\text { rheometer }\end{array}$ \\
\hline
\end{tabular}

\subsection{Determination of the chemical properties}

The interstitial gas contents were obtained using the inert gas fusion technique. The sample was placed in a tin capsule and heated in the graphite crucible at a temperature higher than the melting point of the sample. Oxygen and nitrogen gases were released from the sample and passed through the detectors to measure the quantity of oxygen and nitrogen. The results of these analyses of the DMLS powders, obtained with the ELTRA OHN 2000 system of NECSA, were benchmarked against selected samples analysed in a LECO OHN 836 analyser.

The chemical composition of the Ti6Al4V (ELI) powder was determined using inductively coupled plasma-optical emission spectroscopy (ICP-OES). The technique uses plasma as the excitation source to obtain significant quantitative data. The powder sample was dissolved in an acid solution and fed into a plasma that was set under high temperature conditions. The intensity of the emission lines of the different metal elements was measured in the plasma, and produced qualitative elemental data.

\subsection{Determination of the physical properties}

The morphology of the powder particles was determined by using a JEOL JSM-6510 scanning electron microscope (SEM). The powder samples were carefully mounted on double carbon tape, and all loose powder particles were gently removed before introducing them into the vacuum chamber. In the SEM the secondary electron mode was used to examine the shapes and surfaces of the powder particles in each sample.

For the particle size distribution (PSD) of the different samples, a MICROTRAC SI/S3500 laser diffraction system was used. This method has the ability to measure the distribution of large numbers of particles by analysing the diffraction pattern of laser light, when shone through disperse particles, to obtain statically significant particle counts. These measurements can be represented as graphs by integrating various spherical size coordinates with respect to their volume.

To determine density, the powder samples were analysed using an AccuPyc II 1340 helium pycnometer. The principle of the pycnometer is volumetric displacement of gas and calculation of the ratio of the mass to the volume occupied by that mass. Helium gas is often used in this technique, because its small atomic size allows it to penetrate defects in particles [10]. During measurement a mass of powder particles is poured into the empty vessel of the pycnometer, and then it is filled with helium. The amount of helium filling the empty volume in the vessel and voids around the powder particles is determined. Since the empty volume of the pycnometer is known, and the volume of the helium around the vessel can be measured, the difference between the two volumes determines the volume of the sample. A simple mass measurement of this quantity of powder will then give the density by dividing the mass by the volume.

In general, the flow of powder mainly depends on parameters such as morphology, PSD, and density. Usually, fine particles are tested for flowability and the degree of cohesiveness [11], because in most circumstances fine particles have poor flowability. According to Spierings et al. [12], fine particles can produce 'good' thin layer properties in SLM. However they can also increase the risk of poor flowability, since the inter-particle forces are more pronounced between fine particles, which can easily create cohesive bonds and consequently produce poor flow behaviour. 
The DMLS powder (size range $<40 \mu \mathrm{m}$ ) was measured for flowability using an FT 4 powder rheometer. The method is based on measuring the dynamic properties of powder. It particularly defines the flowability of powder under low stress conditions during the building processes. Briefly, the operating principle of the device is based on twisting a rotating blade downwards and upwards through the bulk powder to obtain different flow patterns. For example, the basic flow energy (BFE) is obtained when the blade overcomes the stress by rotating downwards in an anticlockwise direction, and specific energy (SE) is obtained during the upwards movement of the blade [11]. Higher SE and lower BFE measurements indicate the good flowability of the powder.

\section{RESULTS AND DISCUSSION}

The results obtained by systematically characterising the powder samples with the techniques described in Table 1 are presented here for the following samples:

- $\quad$ DMLS system: Virgin powder samples obtained from five different containers and reused powder samples collected after cycles 11,20 and 25 .

- $\quad$ Concept Laser system: Virgin powder samples taken from three different containers and reused powder samples collected after cycles 2, 3 and 10.

\subsection{Chemical composition}

The chemical compositions of all samples from the DMLS and Concept Laser systems are listed in Tables 2 and 3. The results of the virgin powder were compared with the ASTM F3001 standard [13] and with the analysis provided by the supplier, TLS Technik GMBH.

In Table 2, the compositions of the virgin and the reused Ti6Al4V (ELI) powder samples obtained from the DMLS system after 11, 20, and 25 cycles are shown. Only small changes from the composition of the virgin powder against the number of reuse cycles were observed. The variations of the $\mathrm{O}$ and $\mathrm{N}$ contents were insignificant when compared with the virgin powder results. This indicates that the inert argon atmosphere in the build chamber was successfully maintained at 0 and $\mathrm{N}$ levels that were low enough to prevent diffusion of these gases into the built parts. The Fe content increased from $0.17 \pm 0.0228$ per cent to $0.21 \pm 0.0228$ per cent over the same reuse period, which indicates possible pick-up of Fe from the instruments used to handle and sieve the powder. Even though these small compositional changes were found, the reused powder was still within specification after 25 cycles, and therefore it could be used for subsequent build cycles in the DMLS system.

Table 2: Chemical composition of virgin and reused Ti6Al4V (ELI) powder used in the DMLS system, with standard deviations shown

\begin{tabular}{|c|c|c|c|c|c|c|}
\hline Sample & Source & $\mathrm{AL} \%$ & $\mathrm{~V} \%$ & Fe $\%$ & $\mathrm{~N} \%$ & $0 \%$ \\
\hline \multirow{6}{*}{$\begin{array}{l}\text { Ti6Al4V } \\
\text { (ELI) } \\
\text { virgin } \\
\text { powder }\end{array}$} & $\begin{array}{l}\text { ASTM } \\
\text { F3001 }\end{array}$ & $5.5-6.5$ & $3.5-4.5$ & 0.25 & 0.05 & 0.13 \\
\hline & $\begin{array}{l}\text { TLS } \\
\text { Technik } \\
\text { GmbH }\end{array}$ & 6.34 & 3.94 & 0.25 & 0.006 & 0.082 \\
\hline & NECSA & $\begin{array}{l}5.94 \\
\pm 0.0296 \\
\end{array}$ & $\begin{array}{l}3.90 \\
\pm 0.0283 \\
\end{array}$ & $\begin{array}{l}0.17 \\
\pm 0.0228 \\
\end{array}$ & $\begin{array}{l}0.018 \\
\pm 0.391 \\
\end{array}$ & $\begin{array}{l}0.11 \\
\pm 0.0341 \\
\end{array}$ \\
\hline & LECO & - & - & - & $\begin{array}{l}0.015 \\
\pm 0.000156\end{array}$ & $0.11 \pm 0.00126$ \\
\hline & LECO & - & - & - & $\begin{array}{l}0.013 \\
\pm 0.00273 \\
\end{array}$ & $\begin{array}{l}0.11 \\
\pm 0.00115 \\
\end{array}$ \\
\hline & LECO & - & - & - & $\begin{array}{l}0.015 \\
\pm 0.000469 \\
\end{array}$ & $0.11 \pm 0.00129$ \\
\hline \multirow{3}{*}{$\begin{array}{l}\text { Cycle } 11 \\
\text { Cycle } 20 \\
\text { Cycle } 25\end{array}$} & NECSA & $\begin{array}{l}5.85 \\
\pm 0.0296 \\
\end{array}$ & $\begin{array}{l}3.95 \\
\pm 0.0283 \\
\end{array}$ & $\begin{array}{l}0.23 \\
\pm 0.0228 \\
\end{array}$ & $\begin{array}{l}0.014 \\
\pm 0.391 \\
\end{array}$ & $\begin{array}{l}0.12 \\
\pm 0.0341 \\
\end{array}$ \\
\hline & NECSA & $\begin{array}{l}6.50 \\
\pm 0.0296\end{array}$ & $\begin{array}{l}4.10 \\
\pm 0.0283\end{array}$ & $\begin{array}{l}0.20 \\
\pm 0.0228\end{array}$ & $\begin{array}{l}0.013 \\
\pm 0.391\end{array}$ & $\begin{array}{l}0.11 \\
\pm 0.0341\end{array}$ \\
\hline & NECSA & $\begin{array}{l}5.98 \\
\pm 0.0296 \\
\end{array}$ & $\begin{array}{l}3.80 \\
\pm 0.0283 \\
\end{array}$ & $\begin{array}{l}0.21 \\
\pm 0.0228 \\
\end{array}$ & $\begin{array}{l}0.018 \\
\pm 0.391 \\
\end{array}$ & $\begin{array}{l}0.11 \\
\pm 0.0341 \\
\end{array}$ \\
\hline
\end{tabular}

The results of the virgin powder and reused powder after 1, 2, 3, and 10 build cycles in the Concept Laser system are shown in Table 3 . Some variation in the Al content was observed during the first 
three build cycles, although it remained well within the limits of the specifications. However, after the $10^{\text {th }}$ cycle the $\mathrm{Al}$ content was below the specification range. This indicates loss of Al during the successive build cycles, probably due to the high temperature regions in the immediate vicinity of the laser beam. The 0 content of these samples appeared to be consistently lower than for the DMLS samples over cycles 1 to 3, but after cycle 10 it had increased to 13 per cent. These changes in composition will have to be monitored further to confirm the trend that seems to be appearing. If the deviation from the specification becomes worse, it may not be possible to use the Ti6Al4V (ELI) powder in the Concept Laser system for more than 10 reuse cycles.

Table 3: Chemical properties of virgin and reused Ti6Al4V (ELI) powder used in Concept Laser system

\begin{tabular}{|l|l|l|l|l|l|l|}
\hline Sample & Source & $\mathrm{AL} \%$ & $\mathrm{~V} \%$ & $\mathrm{Fe} \%$ & $\mathrm{~N} \%$ & $0 \%$ \\
\hline $\begin{array}{l}\text { Ti6Al4V (ELI) } \\
\text { virgin } \\
\text { powder }\end{array}$ & ASTM & $5.5-6.5$ & $3.5-4.5$ & 0.25 & 0.05 & 0.13 \\
& F3001 & & & & & \\
\cline { 2 - 7 } & $\begin{array}{l}\text { TLS Technik } \\
\text { GmbH }\end{array}$ & 6.34 & 3.94 & 0.25 & 0.006 & 0.082 \\
\cline { 2 - 7 } & NECSA & 6.04 & 3.83 & 0.16 & 0.010 & 0.079 \\
& & \pm 0.0296 & \pm 0.0283 & \pm 0.0228 & \pm 0.391 & \pm 0.0341 \\
\hline Cycle 1 & NECSA & 6.07 & 3.88 & 0.17 & 0.049 & 0.082 \\
& & \pm 0.0296 & \pm 0.0283 & \pm 0.0228 & \pm 0.391 & \pm 0.0341 \\
\cline { 2 - 7 } Cycle 2 & NECSA & 6.21 & 3.89 & 0.18 & 0.010 & 0.092 \\
& & \pm 0.0296 & \pm 0.0283 & \pm 0.0228 & \pm 0.391 & \pm 0.0341 \\
\cline { 2 - 7 } Cycle 3 & NECSA & 5.96 & 3.84 & 0.17 & 0.011 & 0.096 \\
& & \pm 0.0296 & \pm 0.0283 & \pm 0.0228 & \pm 0.391 & \pm 0.0341 \\
\cline { 2 - 7 } Cycle 10 & NECSA & 4.9 & 3.9 & 0.25 & 0.012 & 0.13 \\
& & \pm 0.0296 & \pm 0.0283 & \pm 0.0228 & \pm 0.391 & \pm 0.0341 \\
\hline
\end{tabular}

\subsection{Morphology}

The morphology and surface features of the powder were investigated at different magnifications in the SEM. However, for ease of comparison, only images at $\times 500$ magnification are presented in this paper. Since the shape and size of the powder particles can influence powder behaviour and compaction during SLM processes, an understanding of the particle morphology and the effect of powder reuse on this is essential.

Figure 2 shows SEM images of powder samples from the DMLS system. Some elongated irregular particles (marked ' $a$ ') were observed both in the virgin powder and after different cycles of reuse; but in all cases the majority of powder particles were spherical. Significant concentrations of small particle sizes and satellites were present in both virgin and reused powders. No clear deterioration of the reused powder was observed after 25 build cycles when compared with the virgin powder.

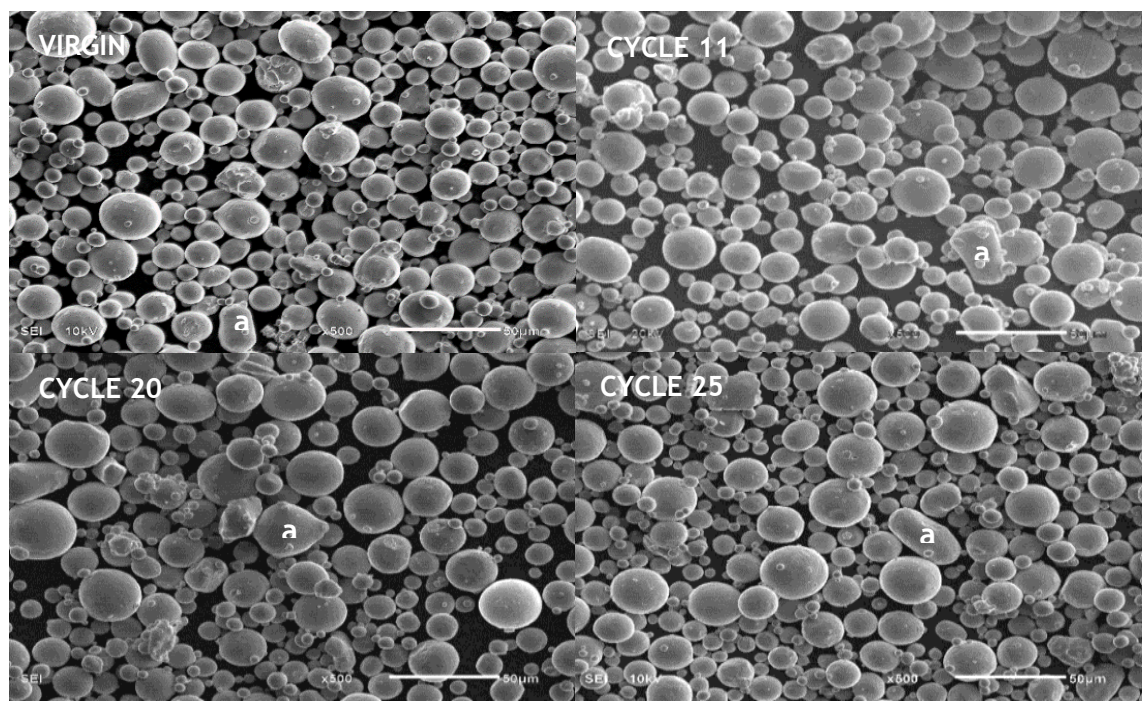

Figure 2: SEM images of Ti6Al4V (ELI) powder from the DMLS system. The white scale bar represents a length of $50 \mu \mathrm{m}$. Magnification: X500 
Figure 3 shows the morphology of the Concept Laser virgin powder and the powder after 2, 3, and 10 build cycles. All powder samples showed small, irregular, rough satellites on some particles (marked ' $b$ ' in the images), but most of the particles were still spherical. No convincing general dissimilarities between the virgin powder and the powder used after 2, 3, and 10 build cycles were detected.

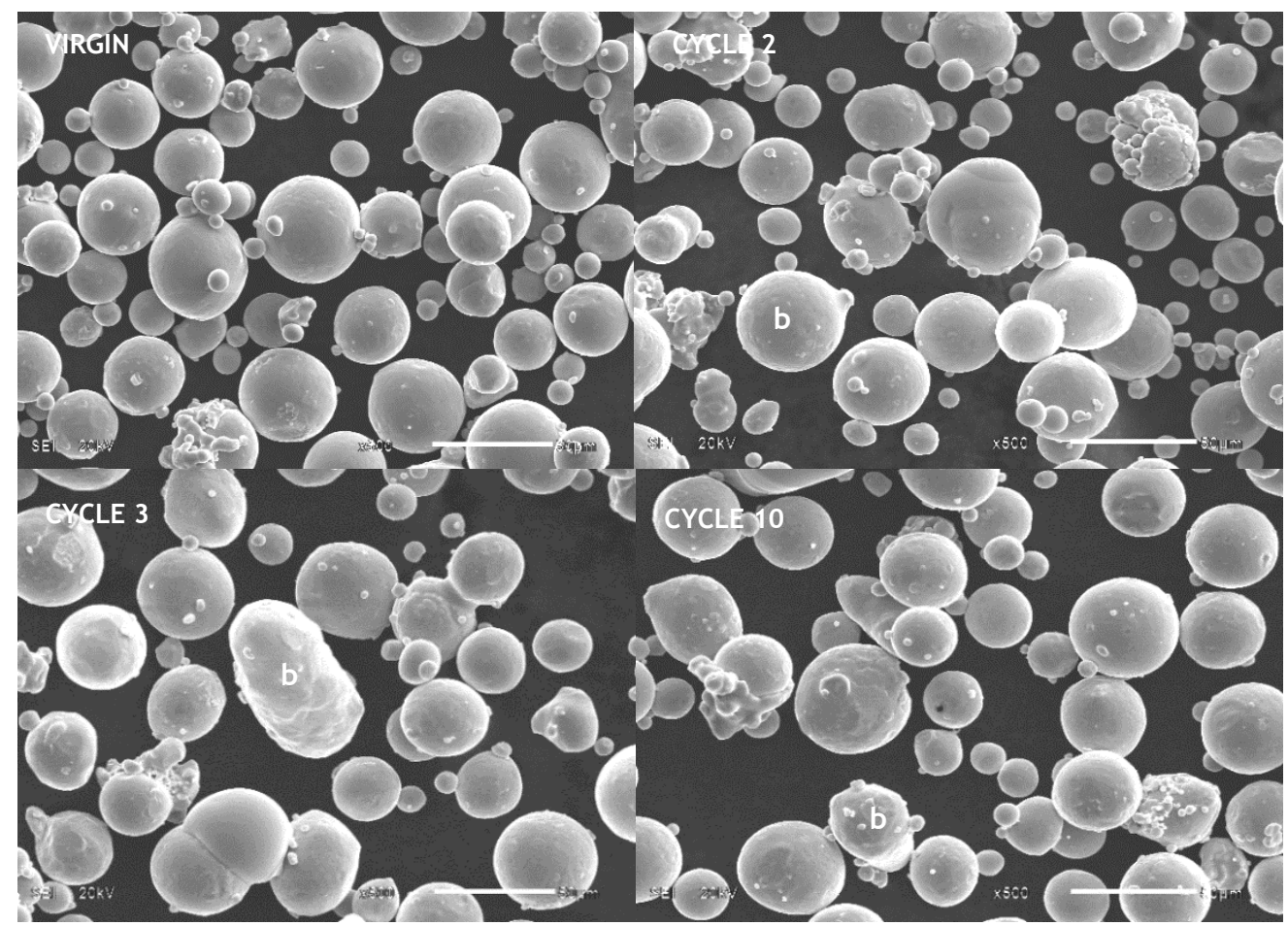

Figure 3: SEM images of Ti6Al4V (ELI) powder from the Concept Laser system. The white scale bar represents a length of $50 \mu \mathrm{m}$. Magnification: X500

\subsection{Particle Size Distribution}

Figures 4 and 5 show the PSD curves for the Ti6Al4V (ELI) samples of the DMLS and Concept Laser systems respectively, as measured by the Microtrac SI/S3500 laser diffraction analyser. The results are presented by integrating various spherical size coordinates with respect to their volume.

Figure 4 shows the PSD curves of the DMLS virgin powder from five different containers and from samples taken after cycle 11 from the top, middle and bottom of the powder dispenser. The overlapping of the graphs of the different virgin powder samples confirms the homogeneity of the batch of powder. No difference was observed between the virgin powder and the Cycle 11 samples taken from the bottom and the middle of the powder dispenser of the DMLS system. However, the Cycle 11 sample taken from the top of the powder dispenser shows a slight shift towards a smaller particle size. This indicates that the top-up of the powder in the container after the $10^{\text {th }}$ cycle affected the PSD of the top section of powder, while the PSD of the powder lower down in the container was not affected. These differences might be due to insufficient mixing of the powder.

As can be seen in Figure 5, the size distributions from the cycles 20 and 25 graphs appear significantly different from the graphs of the previous cycles. The cycle 20 curve shows similarities with the cycle 11 top curve, and a slight shift of the mean to smaller particle sizes. After 25 cycles of reuse, the spread of particle sizes seem to have broadened while maintaining the shift towards the smaller size distribution. This might be attributed to the addition of larger quantities of virgin powder to the powder mix. 


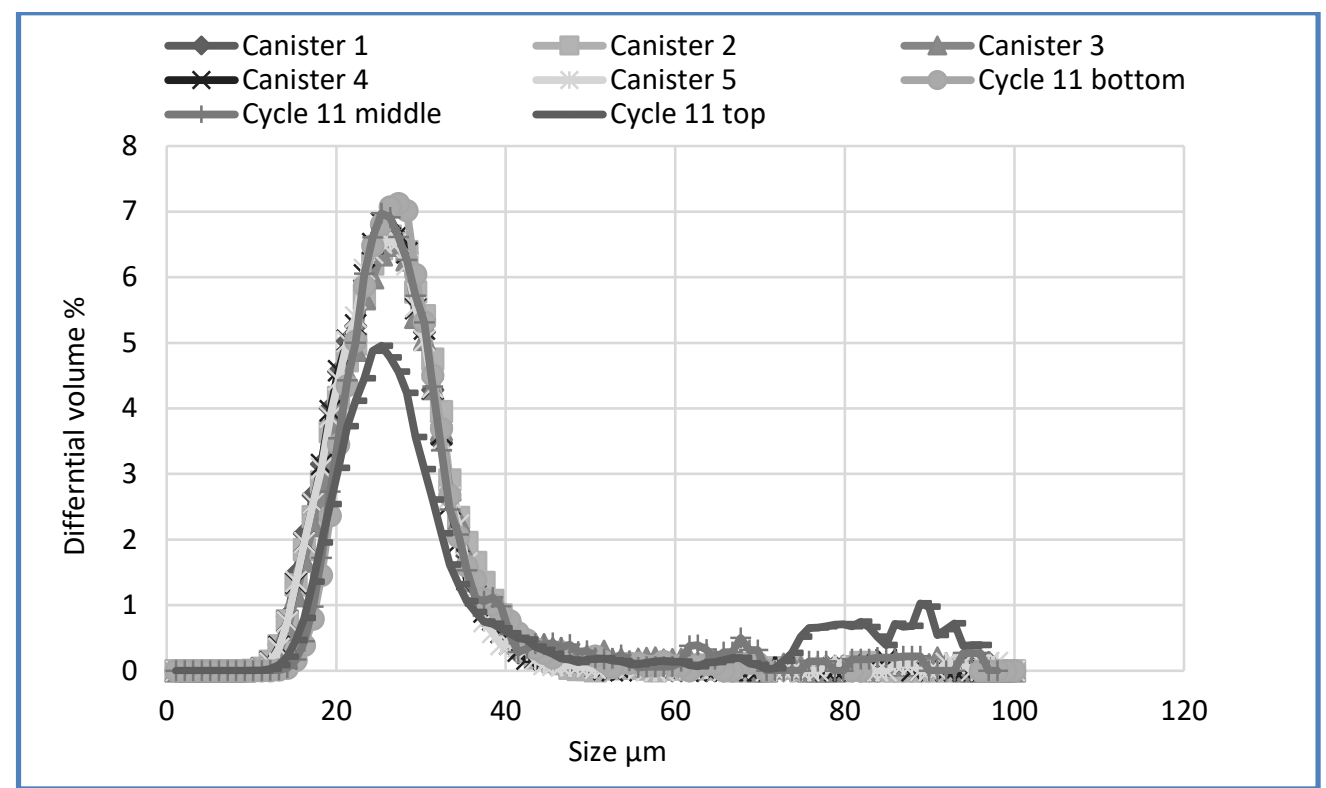

Figure 4: PSD of Ti6Al4V (ELI) powder measured by laser diffraction for virgin powder and reused powder after 11 build cycles from the DMLS system.

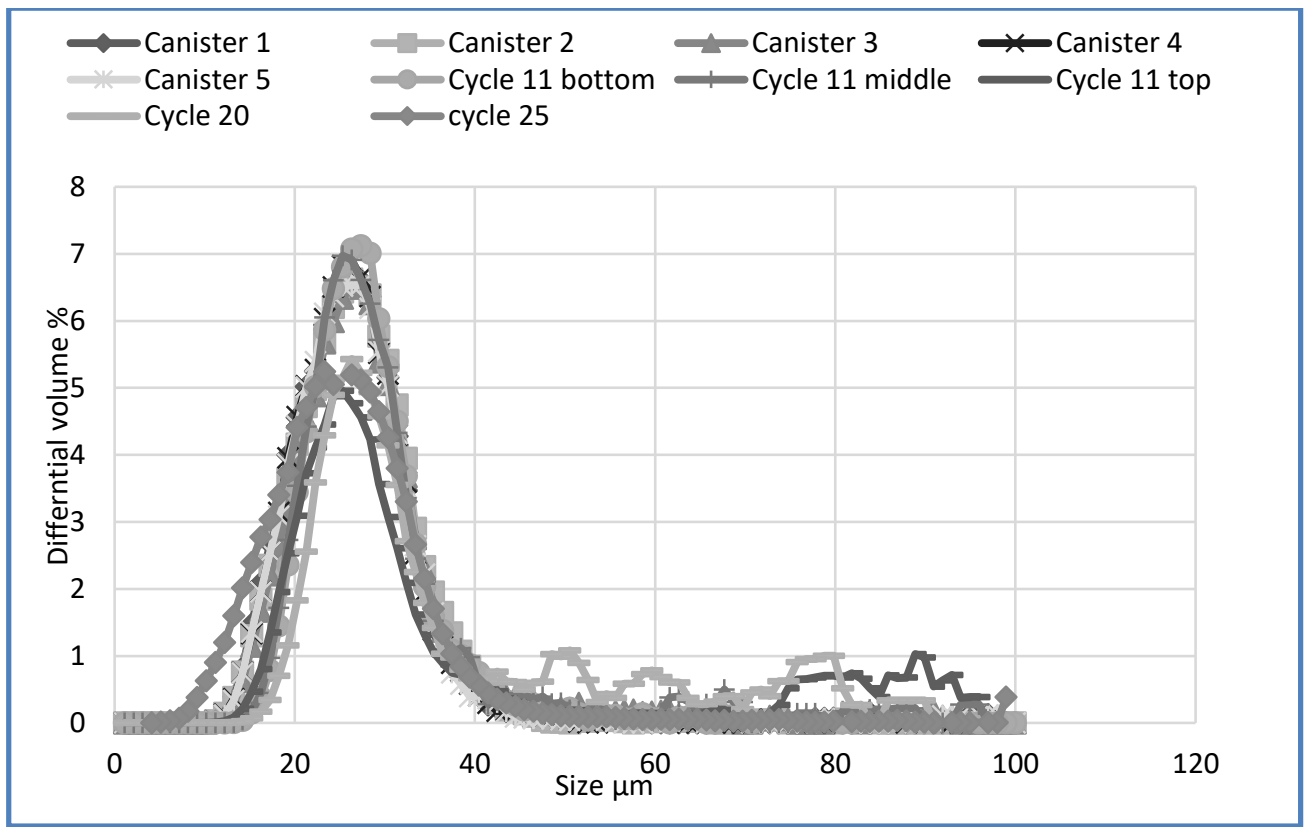

Figure 5: PSD of Ti6Al4V (ELI) powder measured by laser diffraction for virgin powder and reused powder after 25 build cycles from the DMLS system.

Figure 6 shows the PSD results obtained with the powder samples from the Concept Laser system. The PSD curves of the three virgin powder samples appear identical, also confirming the homogeneity of the powder batch. After the first reuse of the powder (cycle 2), there was a significant variation in the PSD observed; and after ten build cycles (cycle 10) the size range of the powder particles seems to have shifted towards larger particle sizes. This shift could be due to more satellites being attached to the particles, and that the ratio of irregularly shaped (elongated) particles in the sample had increased after these build cycles. 


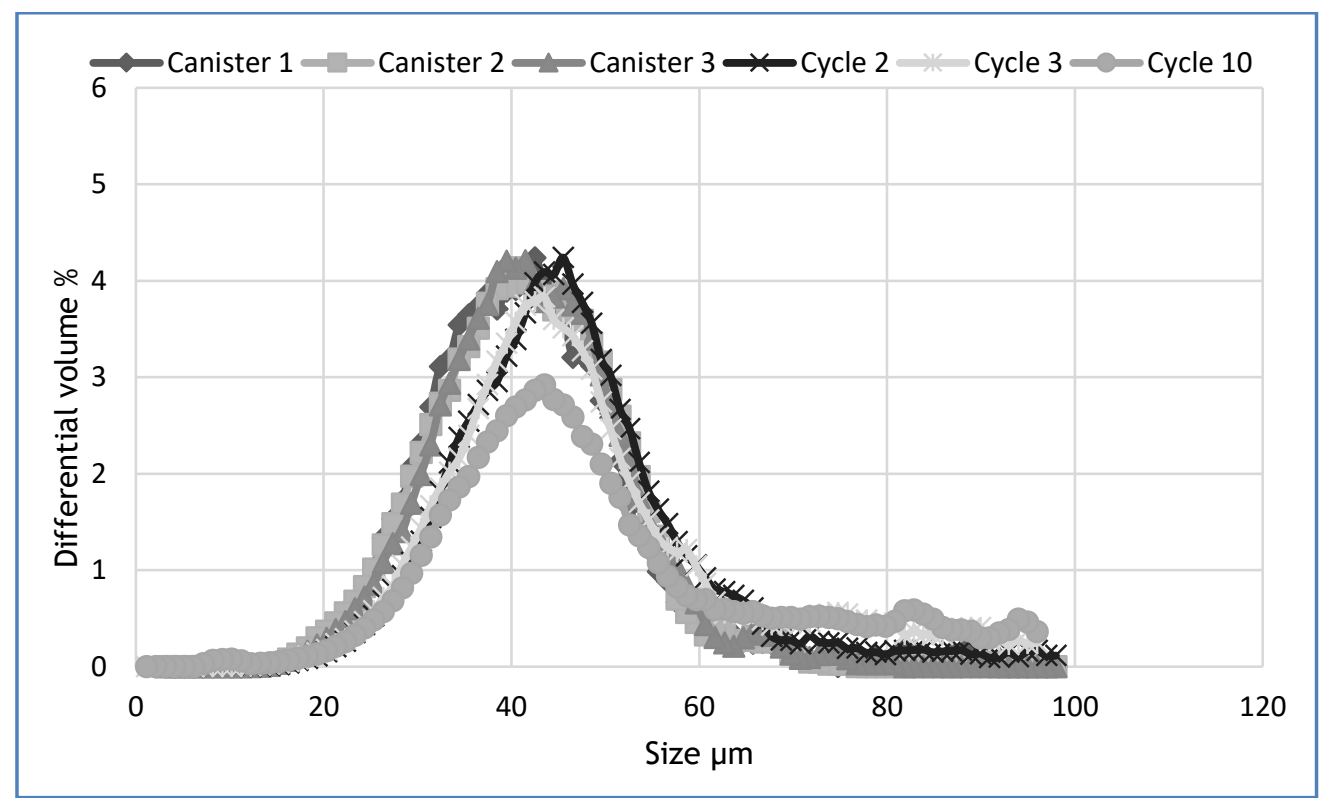

Figure 6: PSD of Ti6Al4V (ELI) powder measured by laser diffraction for virgin powder and reused powder after 10 build cycles from the Concept Laser system.

The powder dispenser was not topped up in the Concept Laser system over the 10 cycles, which could explain the increase in the particle sizes. When observing the PSD results from both SLM systems, it can be seen that throughout the process of the reuse of powders there is a small portion of powder particles that are affected by heat exposure, which are those that lay closer to the build path.

Zhou [9] found that, as powder is reused in the SLM processes, the particle size distribution and morphology is affected. He ascribes this to the sintering of particles due to the laser heating. Increased solid state diffusion between particles that touch each other leads to larger consolidated particles, separated only by grain boundaries, as illustrated in Figure 7.

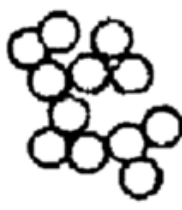

(a)

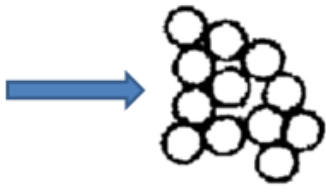

(b)

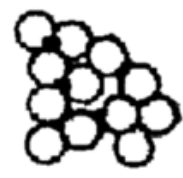

(c)

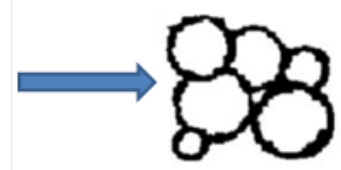

(d)

Figure 7: Description of change in morphology during laser sintering process [9]

\subsection{Density}

Measuring the density of the powder quantifies the extent of defects such as cracks and pores in the particles. Table 4 gives the results of the density measurements of the Ti6Al4V (ELI) powder used in the two SLM systems.

The density of the virgin powder from the DMLS system falls in a range of $4.42 \pm 0.0002$ and $4.41 \pm 0.0002$ after the 25 cycles. The Concept Laser virgin powder shows densities varying from $4.42 \pm 0.0001$ to $4.44 \pm 0.0003$. Both batches of powder have densities close to the theoretical density $\left(4.43 \mathrm{~g} / \mathrm{m}^{3}\right)$ [5]. Since no pores or cracks in the powder particles were observed in the SEM for either the virgin or the reused powder (see Figure 2 and 3), there is no reason to believe that the powder has significant internal pores. 
Table 4: Helium pycnometer results for the density of virgin and reused powders

\begin{tabular}{|l|l|}
\hline Powder types & Powder density $\left(\mathrm{g} / \mathrm{m}^{3}\right)$ \\
\hline DMLS virgin powder & $4.42 \pm 0.0002$ \\
DMLS cycle 11 top & $4.41 \pm 0.0016$ \\
DMLS cycle 11 middle & $4.41 \pm 0.0005$ \\
DMLS cycle 11 bottom & $4.41 \pm 0.0004$ \\
DMLS cycle 20 & $4.42 \pm 0.0002$ \\
DMLS cycle 25 & $4.41 \pm 0.0002$ \\
\hline Concept Laser virgin powder & $4.42 \pm 0.0001$ \\
Concept Laser cycle 1 & $4.44 \pm 0.0003$ \\
Concept Laser cycle 2 & $4.44 \pm 0.0001$ \\
Concept Laser cycle 3 & $4.40 \pm 0.0001$ \\
Concept Laser cycle 10 & $4.41 \pm 0.0005$ \\
\hline
\end{tabular}

\subsection{Flowability}

The cohesiveness of the powder impacts negatively on its flowability. The stronger the cohesion between the powder particles, the lower the flow of the powder becomes. The flowability results of the DMLS virgin powder and after the various numbers of reuse cycles are depicted in Figure 8.

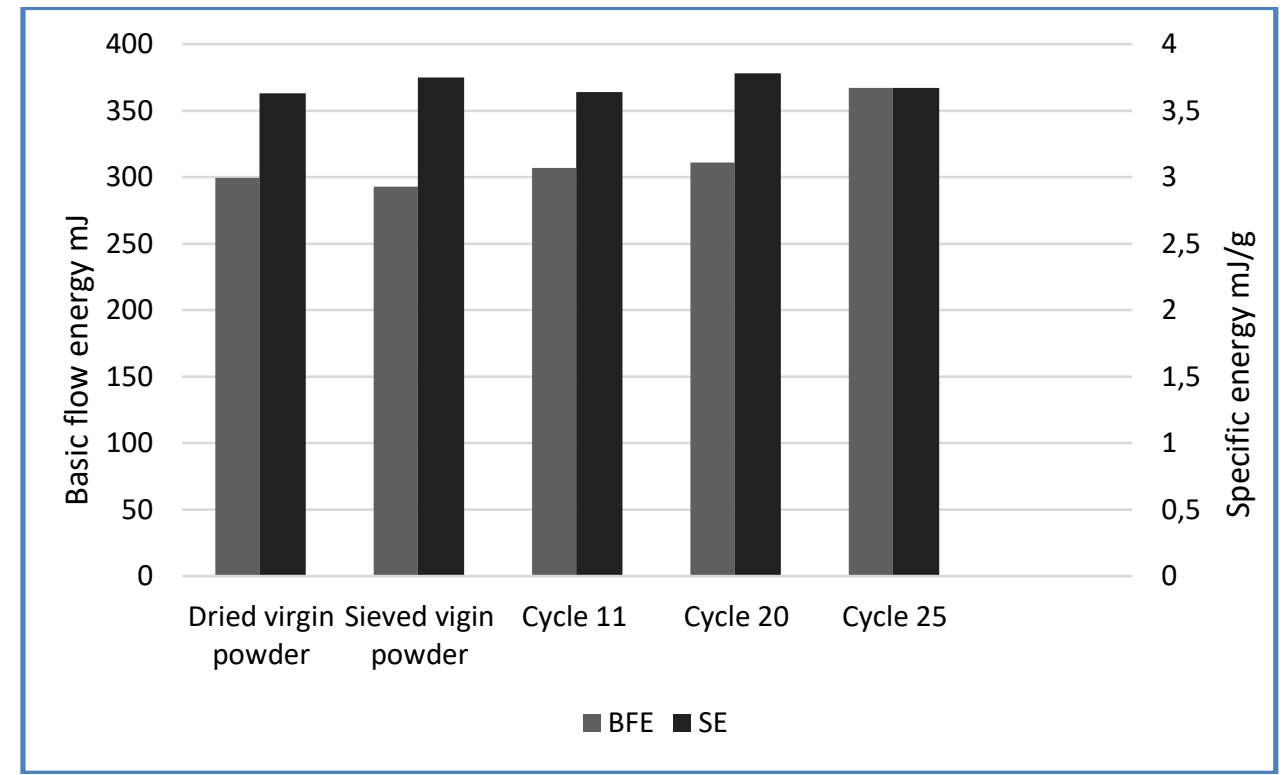

Figure 8: The comparison of flowability results of $40 \mu \mathrm{m}$ powder particles taken from DMLS system

It is well-known from the literature that SE is an indication of the extent of particle agglomeration, because it detects the amount of energy that the blade needs during the upwards movement to break the inter-particulate bonds [11]. The higher SE than BFE measurements shown in Figure 8 represents good powder flow. From these results, the flowability shows insignificant changes between the virgin and the reused powder after 20 cycles. The higher BFE after 25 cycles indicates an increase of finer particles, but this does not impact negatively on flowability.

\section{CONCLUSIONS}

Based on the results presented in this paper, the following conclusions can be drawn:

- The SLM process of both systems operates close to normal room temperature, and therefore the powder is much less affected during reuse than in the case of an EBM system.

- Topping up the reused powder with virgin powder in the DMLS system had a positive effect on maintaining the powder particle size distribution and morphology; therefore the recycling of the powder in the DMLS up to 25 cycles and beyond is quite feasible. 
- $\quad$ Significant changes in powder composition were detected in the Concept Laser powder after 10 reuse cycles, which requires further monitoring of the powder properties after subsequent build cycles to conclude whether powder reuse for more than 10 cycles would be feasible.

\section{ACKNOWLEDGEMENTS}

The financial support of the South African Department of Science and Technology through the Collaborative Programme in Additive Manufacturing is gratefully acknowledged (Contract № CSIRNLC-CPAM-15-MOA-CUT-01).

The collaboration of the CSIR National Laser Centre and Stellenbosch University through the provision of powder samples for this study is highly appreciated.

The physical and chemical property analyses were performed in the CSIR and NECSA test laboratories, and I would like to extend my sincere gratitude for their help with the experimental work.

\section{REFERENCES}

[1] Elias, C.N., Lima, J.H.C.,Valiev, R. \& Meyers, M.A. 2008. Biomedical applications of titanium and its alloy, The Journal of The Minerals, Metals and Materials Society, , 60(3), pp. 46-49, Available at https: //www.tms.org/jom.html.

[2] Thejane, K., Chikosha, S. \& du Preez, W.B. 2016. Characterisation of Ti6Al4V (ELI) powder used by the South Aftrican Collaborative Program in Additive Manufacturing, Proceedings of the 17th Annual International RAPDASA Conference, 2-6 Nov 2016, Paper is available on RAPDASA CD.

[3] Du Preez, W.B. \& se Beer, D.J. 2015. Implementing the South African additive manufacturing technology roadmap - The role of an additive manufacturing centre of competence, South African Jounal of Industrial Engineering, 26(2), pp. 85-92.

[4] Seyda, V., Kaufmann, N. \& Emmelmann, C. 2012. Investigating of aging processes of Ti6Al4V powder material in laser melting. ROMEO Blue Journal, (39), pp. 425-431 Available at: http://www.sciencedirect.com.

[5] Tang, H.P., Qian, M., Liu, N., Zhang, X.Z., Yang, G.Y. \& Wang, J. 2015. Effect of powder reuse times on additive manufacturing of Ti6Al4V by selective electron beam melting, The Journal of The Minerals, Metals and Materials Society, 67(3), pp. 555-563.

[6] World Health Oganization. 2005. Guidelines for Sampling of Pharmaceutical Products and related Materials, World Health Organisation Technical Report Series, no 929, Annex 4.

[7] ASTM International F3049-14. 2014. Standard guide for characterising properties of metal powders used for additive manufacturing processes. 100 Barr Habor Drive, PO Box C700, West Conshohocken, PA 194282959, United States, www.astm.org.

[8] Javed, A., Shahid, K., Durrani, N.A., Chught, A.I. \& Shahid, K.A. 1996. Determination of gaseous elements in metal and metal powders, The Journal of the Chemical Society of Pakistan, 18(1), pp. 14-18.

[9] Zhou, Y. 2014. Characterisation of the porosity and pore behavior during the sintering process of 420 stainless steel samples produced with gas and water atomized powder using powder based 3D printing. Thesis approved $2^{\text {nd }}$ April 2014 at University of Pittsburgh.

[10] Slotwinski, J.A., Garboczi, E.J., Stutzman, P.E., Ferraris, C.F., Watson, S.S. \& Peltz, M.A. 2014. Characterisation of metal powders used for additive manufacturing, The Journal of Research of the National Institude of Standards and Technology, 119, pp. 460-491.

[11] Leturia, M., Benali, M., Lagarde, S., Ronga, I. \& Saleh, K. 2014. Characterisation of flow properties of cohesive powders: A comparative study of traditional and new testing methods, RoMEO Green Journal, 253, pp 406-423. Available at: http://www.elsevier.com.

[12] Spierings, A.B., Voegtlin, M., Bauer, T. \& Wegener, K. 2015. Powder flowability characterisation methodology for powder bed based metal additive manufacturing, RoMEO Blue Journal, 1(1-2), pp 9-20, Available at https: / /www.researchgate.net.

[13] ASTM International F3001-14. 2014. Standard specification for additive manufacturing Titanium-6 Aluminum-4 Vanadium ELI (Extra Low Interstitial) with powder bed fusion. 100 Bar Harbor Drive, PO Box C-700, West Conshohocken, PA 19428-2959, United States, www.astm.org. 